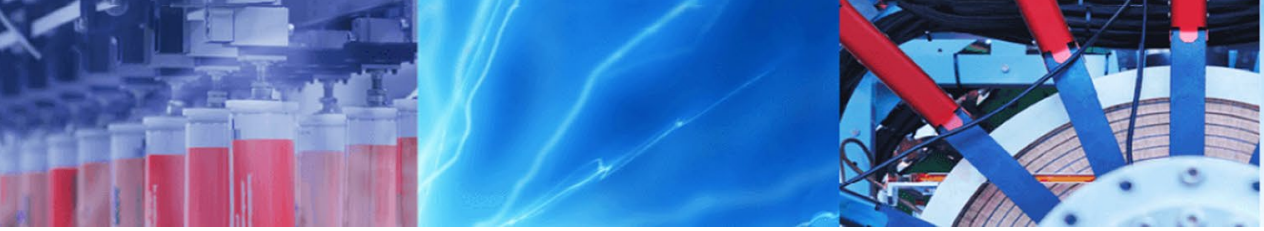

Research Article

\title{
An analysis of retailer's inventory in a two-echelon centralized supply chain co-ordination under price-sensitive demand
}

\author{
Abhijit Barman ${ }^{1} \cdot$ Rubi Das $^{1} \cdot$ Pijus Kanti De ${ }^{1}$
}

Received: 3 August 2020 / Accepted: 25 November 2020 / Published online: 5 December 2020

(c) Springer Nature Switzerland AG 2020

\begin{abstract}
As the industrial environments become more competitive, managing specific inventory levels and coordination between channel members of a companies supply chain is very much crucial. In this paper, we have analyzed a two-echelon supply chain containing a manufacturer and a retailer in which the manufacturer offers a single product to the retailer and the retailer takes the responsibility of managing the inventory of the product. The products deteriorate at the retailer warehouse at a constant deterioration rate. We have generalized our model for two different demand functions faced by the retailer from the customers' side. The demand functions are (a) a linear function of price (b) an iso-elastic function of price. The shortage is also allowed and partially backlogged with a constant backlogging rate. Total profit of the supply chain under two different demand scenarios is evaluated for a joint centralized coordination. The prime objective of our paper is to compare the total profit under two different demand functions in joint centralized coordination such that the channel member can decide their optimal sales price, inventory scheduling of retailer, ordering lot size to maximize the total profit. A numerical example has been illustrated to validate the theoretical results. Also, sensitivity analysis of some key parameters is carried out which gives some managerial applications. The findings of this paper demonstrate that linear demand would increase the joint profit of a centralized system. This analysis has an important guiding significance for the supply chain coordination of deteriorating items under linear and iso-elastic demand.
\end{abstract}

Keywords Supply chain · Inventory · Deterioration · Price-sensitive demand · Partial backlogging · Shortage

\section{Introduction}

Inventory is the source of a large part of the costs of organizations which affects directly the pricing strategy. When products are purchased from an outside supplier it is also necessary to deal with the replenishment time for best optimal decisions. Decision-maker uses price as a decision variable which needs to be optimized and demand is also considered as price-sensitive [2,4]. Hence pricing and inventory control are necessary to increase the ability of an organization to be competitive in the market and it is also very eminent when considered product deterioration. Deterioration of various products is a natural occurrence for production inventory which occurs due to damage, dryness, evaporation, spoilage, etc. It also reduces the quality and quantity of stored products. In recent studies of the inventory model, many researchers have investigated their models with deterioration of products $[12,18$, 24]. To evaluate the pricing and inventory strategy, noninstantaneous deterioration of items was considered in an EOQ model under price and time-sensitive demand [15]. Food wastage was decreased through pricing strategy and maximize the profit under price-sensitive demand in [27]. An inventory mechanism with a price-dependent demand pattern evaluated the order amount, sales price, and cyclelength of deteriorating product [5]. Other factors like

Abhijit Barman, abhijitmath93@gmail.com; Rubi Das, rubidas1118@gmail.com; Pijus Kanti De, pijusde@gmail.com|'Department of Mathematics, National Institute of Technology Silchar, Silchar, Assam 788010, India. 
advertising play a key role in pricing decisions of deteriorating inventory model in [9].

In many earlier studies, the demand function is assumed to be constant. But for a variety of items like soft drinks, fruit juice, detergent, etc. this assumption is violated and demand is often assumed as iso-elastic [13] and infrequently depend on selling price. The exponential and negative power of the price form of demand curve was used to determine optimum cycle length, deteriorating length, and sales price of a deteriorating inventory model [17]. Optimum sales price, replenishment number, and full-cycle length for iso-elastic price-sensitive demand in a deteriorating EOQ model were discussed in [14]. An EOQ model for deteriorating items that specify the demand explicitly in the multivariate form of price, freshness, and display of stocks in [8]. Two different demand function with iso-elastic price-sensitive form and linear price- and stock-sensitive demand form has been discussed in [20] to study a deteriorating inventory model for different credit periods.

All of the above literature, various policies are determined for a single decision-maker to optimize its own performance. In today's competitive market, organizations and businesses have enlarged their profitability by utilizing co-ordination strategy. Supply chain management is considered the most advantageous ways to enhance benefits for the organization. Today, rapid urbanization and competing global markets increase the importance of coordination between independent organizations. In a coordinated supply chain, various channel members work jointly to minimize system-related costs and get competitive advantages. An integrated inventory system for one supplier-one customer problem has been performed in for companies' supply chain management mechanism [11]. The profit of a manufacturer-retailer supply chain was maximized with the level of inventory-dependent demand under discount contract [28]. Different supply chain policies containing a manufacturer and a retailer in which upstream member retailer inventory contains multiple costs for price and inventory-level-dependent demand [21]. An enmesh marketing and operations deal with information asymmetry and its profitability implications under rebates, as the trade incentive of interest in a two-stage supply chain has been discussed in $[3,19]$. An integrated inventory model for a single manufacturer and multiple buyers under price-sensitive demand studied in [1].

Supply chain members manage their inventory level and faced deterioration of products during stock due to different geographical locations. Many studies such as [22, 26] analyze the pricing strategy and inventory decisions of deteriorated products through supply chain structure. To minimize the cost of deteriorating items, a two-layer supply chain mechanism has been established in [6] to evaluate replenishment time and total credit under constant demand. A two-stage supply chain mechanism considering the deterioration of product with linear pricesensitive demand was discussed in [7].

The decision-making process of an organization is characterized as centralized and decentralized. In a centralized structure, a central decision-maker controls the chain's desired outcome such that all the members of the chain can gain together. This decision-making process is our present paper concern. In the decentralized structure, each channel member autonomously picks his techniques and therefore the general framework effectiveness may not necessarily be optimized. A decentralized structure of supply chain with linear selling price-dependent demand to optimize sales price, number of shipments, and cycle length for minimizing overall cost were studied in [23]. A manufacturer-retailer supply chain mechanism was illustrated under the linear and iso-elastic pattern of the price-sensitive demand function for both centralized and decentralized structures in [10]. A closed-loop supply chain model was addressed for re-manufactured products under price-sensitive for both centralized and decentralized cases in [16].

In Table 1, we have summarized some main assumptions and objectives of the recent literature to make it simpler for the readers to appreciate the contribution of our model. There are lot of researchers generalized different decision-making strategies for different demand patterns under a single decision-maker as well as multiple stages containing supply chain model but the purpose of this paper how both linear and iso-elastic price-sensitive demand pattern together effect on joint pricing and inventory policy of a two-echelon supply chain. We have designed a two-echelon supply chain model considering various assumptions like deterioration of the product, shortage with constant backlogging in-retailer inventory but neglect the inventory of the manufacturer. Also, we have seen from Table 1 that no work has previously done considering the effect of two different demand patterns in supply chain scenario. Our model is more prominent for the deteriorated products such as fruits, vegetables, sweets, etc. The demand for these products is mainly dependent on the sales price. These products sell through the retailer or directly to the customer and market decisions of the products are managed by the channel members together or individually as indicated by their significance, singular benefit, and connection. One of the practical examples of our proposed model is ice-cream factory. During any season, the demand for ice-cream increases linearly and nonlinearly with the selling price.

Our investigation contrasts from the earlier studies in the accompanying significant aspects. Firstly, we have considered the demand of the customers (1) linear function 
Table 1 Summary of existing literature which are closely related to this model

\begin{tabular}{|c|c|c|c|c|c|c|c|c|}
\hline \multirow[t]{2}{*}{ Authors } & \multirow[t]{2}{*}{ Year } & \multirow{2}{*}{$\begin{array}{l}\text { Sup- } \\
\text { plychain } \\
\text { scenario }\end{array}$} & \multicolumn{2}{|c|}{ Demand policy } & \multirow[t]{2}{*}{ Deterioration } & \multirow[t]{2}{*}{ Shortages/backlogging rate } & \multirow{2}{*}{$\begin{array}{l}\text { Objec- } \\
\text { tive func- } \\
\text { tion }\end{array}$} & \multirow[t]{2}{*}{ Optimal decision } \\
\hline & & & Linear & Iso-elastic & & & & \\
\hline [18] & 2004 & $\times$ & $\times$ & $\checkmark$ & $\checkmark$ & $x$ & Profit & $\begin{array}{l}\text { Price } \\
\text { Order quantity }\end{array}$ \\
\hline [3] & 2008 & $\checkmark$ & $\checkmark$ & $\checkmark$ & $x$ & $x$ & Profit & $\begin{array}{l}\text { Price } \\
\text { Rebate value }\end{array}$ \\
\hline [15] & 2012 & $x$ & $\checkmark$ & $\times$ & $\checkmark$ & Allowed/time-varying & Profit & $\begin{array}{l}\text { Price } \\
\text { Time upto zero inventory } \\
\text { Cycle duration } \\
\text { Order quantity }\end{array}$ \\
\hline [27] & 2012 & $x$ & $\checkmark$ & $x$ & $\checkmark$ & $x$ & Profit & $\begin{array}{l}\text { Price } \\
\text { Price discount rate }\end{array}$ \\
\hline [21] & 2015 & $\checkmark$ & $\checkmark$ & $x$ & $x$ & $x$ & Profit & $\begin{array}{l}\text { Price } \\
\text { Order quantity }\end{array}$ \\
\hline [23] & 2016 & $\checkmark$ & $\checkmark$ & $x$ & $x$ & $x$ & Cost & $\begin{array}{l}\text { Price } \\
\text { Number of shipments }\end{array}$ \\
\hline [10] & 2016 & $\checkmark$ & $\checkmark$ & $\checkmark$ & $x$ & $x$ & Profit & $\begin{array}{l}\text { Price } \\
\text { Order quantity } \\
\text { Order quantity }\end{array}$ \\
\hline [25] & 2018 & $x$ & $\checkmark$ & $x$ & $\checkmark$ & Allowed/time-varying & Profit & $\begin{array}{l}\text { Price } \\
\text { Order quantity } \\
\text { Replenishment-time }\end{array}$ \\
\hline [14] & 2019 & $\times$ & $x$ & $\checkmark$ & $\checkmark$ & $x$ & Profit & $\begin{array}{l}\text { Price } \\
\text { Inventory scheduling }\end{array}$ \\
\hline Our contribution & - & $\checkmark$ & $\checkmark$ & $\checkmark$ & $\checkmark$ & Allowed/constant & Profit & $\begin{array}{l}\text { Price } \\
\text { Order quantity } \\
\text { Time upto zero inventory }\end{array}$ \\
\hline
\end{tabular}

of selling price. (2) iso-elastic form of selling price. Secondly, under price-dependent demand, consideration of the deterioration of products plays an important role in pricing and inventory decisions to analyze the optimal profit of the supply chain. Thirdly, a shortage at the retailer warehouse is allowed with a constant backlogging rate of $\delta$. Fourthly, we study the performance of our proposed manufacturer-retailer supply chain in a joint centralized structure. Lastly, a comparative study on linear and isoelastic demand function on our proposed joint centralized supply chain strategy are examined.

Our work aims to compare joint pricing and replenishment strategies throughout the supply chain using two different types of demand patterns. The proposed analysis gives two aspects of a supply chain model (1) increasing profitability from the customer by optimizing sales price and order amount of a product under different demand scenario, (2) reducing cost of material flow between supply chain members. The results of considering all these demand functions greatly influence the total profit of business organizations and their decisions.

The paper is structured as follows. Section 2 is based on subsection "Notations and assumptions" of the model, "Mathematical Formulation" and the "Solution methodology" under centralized coordination with theoretical results of the model. In Sect. 3, theoretical results are demonstrated by a numerical example and a sensitivity analysis is conducted. Lastly, conclusion and future research direction are presented in Sect. 4.

\section{Model formulation and solution methodology}

\subsection{Notations and assumptions}

\subsubsection{Notations}

The following notations are used to establish the model.

\begin{tabular}{ll}
\hline Notations & Descriptions \\
\hline$p$ & Selling price for the item (/unit) \\
$T_{1}$ & Time length up to zero inventory \\
& level of the retailer \\
$l_{1}(t)$ & Retailer inventory level at time $t$ \\
& for the item, $0<t<T_{1}$ \\
\hline
\end{tabular}




\begin{tabular}{|c|c|}
\hline Notations & Descriptions \\
\hline$I_{2}(t)$ & $\begin{array}{l}\text { Retailer inventory level at time } t \\
\text { for the item, } T_{1}<t<T\end{array}$ \\
\hline$R(p)$ & $\begin{array}{l}\text { Demand rate at time } t \text { for the } \\
\text { item }\end{array}$ \\
\hline$Q$ & $\begin{array}{l}\text { Total order quantity of the item } \\
\text { (units) }\end{array}$ \\
\hline$q$ & $\begin{array}{l}\text { Retailer on-hand inventory of the } \\
\text { item (units) }\end{array}$ \\
\hline$S$ & $\begin{array}{l}\text { Backlogging size (units) during } \\
{\left[T_{1}, T\right] \text { of retailer }}\end{array}$ \\
\hline O & $\begin{array}{l}\text { Retailer ordering cost of the item } \\
\text { (/cycle ) }\end{array}$ \\
\hline$T$ & The duration of the cycle \\
\hline M & $\begin{array}{l}\text { Manufacturing cost for the item } \\
\text { (/unit ) }\end{array}$ \\
\hline$w$ & $\begin{array}{l}\text { Wholesale price of the manufac- } \\
\text { turer (/unit) }\end{array}$ \\
\hline$h$ & $\begin{array}{l}\text { Retailer holding cost for the item } \\
\text { (/unit/time unit ) }\end{array}$ \\
\hline$d$ & $\begin{array}{l}\text { Retailer deterioration cost for the } \\
\text { item ( / unit /time unit) }\end{array}$ \\
\hline$s$ & $\begin{array}{l}\text { Retailer shortage cost for the } \\
\text { item ( / unit /time unit) }\end{array}$ \\
\hline$\theta$ & Deterioration rate for the item \\
\hline$T P_{M}$ & Total profit of the manufacturer \\
\hline$T P_{R}$ & Total profit of the retailer \\
\hline$T P$ & Total profit \\
\hline
\end{tabular}

\subsubsection{Assumptions}

The following assumptions are considered to develop the model.

1. The supply chain consists of one manufacturer and one retailer with a single-item inventory system.

2. Demand rates of the items are considered as (a) $R(p)=a-b p$ with $b>0$, price elasticity and $a$ basic demand, where $a>>b$. (b) $R(p)=d_{0} p^{-k}$ where $d_{0}>0$, is a scaling factor and $k>1$ is the price elasticity parameter. This form of demand is known as iso-elastic demand.
3. The on-hand inventory of the products at the retailer warehouse deteriorates with a constant deterioration rate of $\theta,(0<\theta<1)$. Also, it is presumed that deteriorated products are not replenished during $\left[0, T_{1}\right]$.

4. The supply chain system operates for a prescribed period of $T$ units (planning horizon). At time $t=0$ the initial inventory of the retailer is $q$ and $t=T_{1}$ the inventory level of the retailer is zero. Then the shortage occurs up to next replenishment time $T$. Clearly, $T>T_{1}$.

5. Shortages are allowed and partially backlogged with a constant backlogging rate $\delta$. The shortage period is $\left(T-T_{1}\right)$.

6. Lead time is negligible.

\subsection{Mathematical formulation}

In this paper, we consider a two-layered supply chain comprising of a manufacturer and a retailer. In Fig. 1, we see that the manufacturer delivers the product to the retailer at a wholesale price of $w$. Retailer ordering lot size from the manufacturer is $Q$. Some products are deteriorated at retailer inventory which is described elaborately in Sect. 2.2.1 and Fig. 2. The retailer faces a demand $R(p)$ from the customer side and sells the products at a price $p$ to the customer.

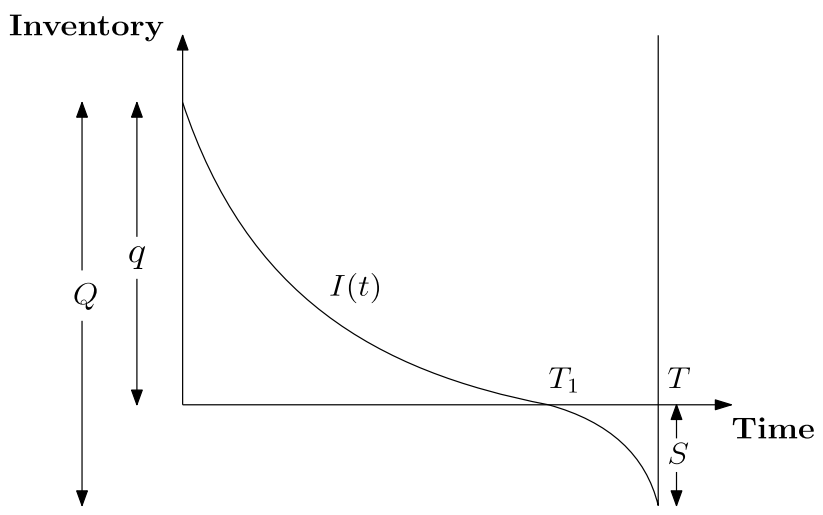

Fig. 2 Retailer's inventory diagram

Fig. 1 Supply chain structure

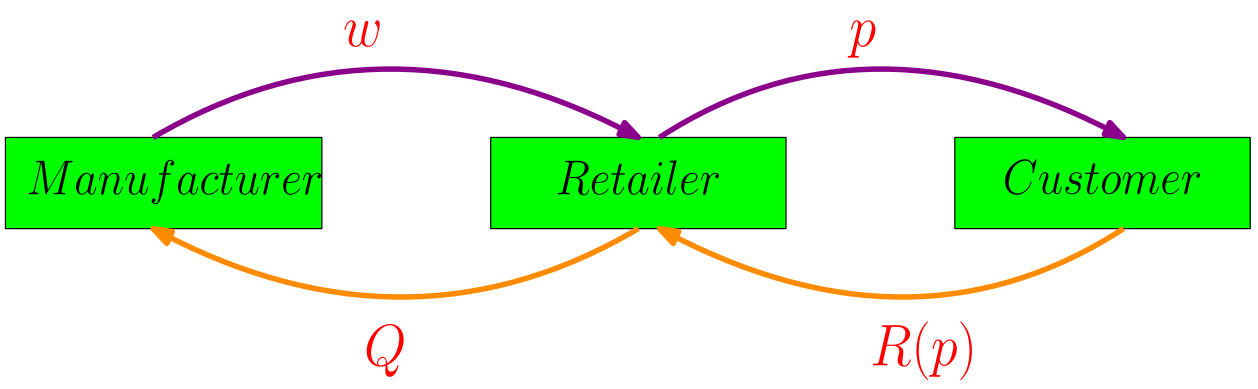




\subsubsection{Retailer profit function}

The retailer inventory level follows the pattern presented in Fig. 2. At the beginning of the retailer inventory cycle, inventory starts with an on-hand inventory $l_{1}(0)=q$ at time $t=0$. This stock is reduced to meet the customers' demand with deterioration of product and inventory level reaches zero at time $t=T_{1}$. Then shortage at the retailer warehouse appears which is partially backlogged with a constant backlogging rate $\delta$ at time-interval $\left[T_{1}, T\right]$. We mention the amount of backlogging is $S$. So, the total order quantity placed by the retailer to the manufacturer is $q+S$.

During the time interval $\left[0, T_{1}\right]$, the retailer's inventory follows the following differential equation:

$\frac{\mathrm{d} l_{1}(t)}{\mathrm{d} t}+\theta l_{1}(t)=-R(p)$

with the initial condition $l_{1}(0)=q$ and boundary condition $I_{1}\left(T_{1}\right)=0$. By solving $(1)$, it yields

$l_{1}(t)=R(p)\left[e^{\theta\left(T_{1}-t\right)}-1\right], \quad t \in\left[0, T_{1}\right]$

Finally, in the interval $\left[T_{1}, T\right]$, the shortage occurs and demand is partially backlogged. Thus, the below differential equation represents the inventory status during the shortage

$\frac{\mathrm{d} l_{2}(t)}{\mathrm{d} t}=-\delta R(p)=-\delta R(p)$

with the boundary condition $I_{2}\left(T_{1}\right)=0$ the solution of (3) is

$I_{2}(t)=\delta R(p)\left(T_{1}-t\right), \quad t \in\left[T_{1}, T\right]$

If we put $t=T$ into (4), the maximum amount of backlogging will be obtained as follows

$S=-I_{2}(T)=-\delta R(p)\left(T_{1}-T\right)$

Then the total order quantity per cycle $(Q)$ is the sum of $q$ and $S$, i.e.,

$Q=q+S=R(p)\left[\frac{e^{\theta T_{1}}-1}{\theta}-\delta\left(T_{1}-T\right)\right]$

Now, we have calculated different inventory costs and sales revenue per unit time per cycle that consist of the following six components:

1. Ordering cost $=\frac{O}{T}$

2. Retailer's purchasing cost $=\frac{w Q}{T}$

$$
=\frac{w R(p)}{T}\left[\frac{e^{\theta T_{1}}-1}{\theta}-\delta\left(T_{1}-T\right)\right]
$$

3. Holding cost $=\frac{h}{T} \int_{0}^{T_{1}} I_{1}(t) \mathrm{d} t$

$$
=\frac{h R(p)}{T \theta}\left[\frac{e^{\theta T_{1}}}{\theta}-T_{1}-\frac{1}{\theta}\right]
$$

4. Deterioration cost $=\frac{d}{T}\left[l_{1}(0)-\int_{0}^{T_{1}} R(p) \mathrm{d} t\right]$

$=\frac{d R(p)}{T}\left[\frac{e^{\theta T_{1}}-1}{\theta}-T_{1}\right]$

5. Shortage cost $=\frac{s}{T} \int_{T_{1}}^{T}\left[-I_{2}(t)\right] d t$

$=-\frac{s \delta R(p)}{T}\left[\Pi_{1}-\frac{T_{1}^{2}}{2}-\frac{T^{2}}{2}\right]$

6. Sales revenue $=\frac{p}{T} \int_{0}^{T} R(p) \mathrm{d} t$

$=p R(p)$

Therefore, the total profit of the retailer per unit time per cycle (denoted by $T P_{R}$ ) is obtained by:

Total profit $=$ Sales revenue - Ordering cost - Purchasing cost - Holding cost - Deterioration cost- Shortage cost.

$$
\begin{aligned}
T P_{R} & =\frac{p T R(p)}{T}-\frac{O}{T}-\frac{w R(p)}{T}\left[\frac{e^{\theta T_{1}}-1}{\theta}-\delta\left(T_{1}-T\right)\right] \\
& -\frac{h R(p)}{T \theta}\left[\frac{e^{\theta T_{1}}}{\theta}-T_{1}-\frac{1}{\theta}\right]-\frac{d R(p)}{T}\left[\frac{e^{\theta T_{1}}-1}{\theta}-T_{1}\right] \\
& +\frac{s \delta R(p)}{T}\left[T_{1}-\frac{T_{1}^{2}}{2}-\frac{T^{2}}{2}\right]
\end{aligned}
$$

with $p>w, w>0, p \in R^{+}, T_{1} \in R^{+}$.

Rearranging Eq. (12) we get,

$$
\begin{aligned}
T P_{R} & =\frac{R(p)}{T}\left[p-\left(w+d+\frac{h}{\theta}\right)\left(\frac{e^{\theta T_{1}}-1}{\theta}\right)-w \delta T\right. \\
& \left.+\left(w \delta+s \delta+d+\frac{h}{\theta}\right) T_{1}-s \delta\left(\frac{T_{1}^{2}}{2}+\frac{T^{2}}{2}\right)\right]-\frac{O}{T}
\end{aligned}
$$

with $p>w, w>0, p \in R^{+}, T_{1} \in R^{+}$.

\subsubsection{Manufacturer profit function}

There are no different individual cost of the manufacturer. The manufacturer makes the products and delivers them to the retailer with zero lead time. Products are stored for a short period at the manufacturer warehouse. So, we neglect deterioration cost, inventory cost and optimized the manufacturer overall profit $\left(T P_{M}\right)$ per unit time.

$$
\begin{aligned}
T P_{M} & =(w-M) \frac{Q}{T} \\
& =(w-M) \frac{R(p)}{T}\left[\frac{e^{\theta T_{1}}-1}{\theta}-\delta\left(T_{1}-T\right)\right]
\end{aligned}
$$

with $w>M, w \in R^{+}, T_{1} \in R^{+}$. 


\subsection{Solution methodology}

The manufacturer and the retailer are both decision-makers and they jointly optimize the profit function for both the demand scenario. This strategy to solve the mathematical model is a centralized system. Let, $\operatorname{TP}\left(p, T_{1}\right)$ be the joint average profit function of the supply chain that is the sum of manufacturer's and retailer's average profit.

$$
\begin{aligned}
T P\left(p, T_{1}\right) & =T P_{R}+T P_{M} \\
& =\frac{R(p)}{T}\left[p-\left(M+d+\frac{h}{\theta}\right)\left(\frac{e^{\theta T_{1}}-1}{\theta}\right)\right. \\
- & M \delta T+\left(M \delta+s \delta+d+\frac{h}{\theta}\right) T_{1} \\
- & \left.s \delta\left(\frac{T_{1}^{2}}{2}+\frac{T^{2}}{2}\right)\right]-\frac{O}{T}
\end{aligned}
$$

with $p>w>M>0, T>T_{1}, p \in R^{+}, T_{1} \in R^{+}$.

The corresponding optimization problem for the overall supply chain can be written as

$$
\max \quad T P\left(p, T_{1}\right)
$$

such that: $\quad p>w>M>0$,

$$
T>T_{1}, p \in R^{+}, T_{1} \in R^{+}
$$

\subsubsection{Supply chain profit under linear price-sensitive demand}

For $R(p)=a-b p$, the joint average supply chain profit is

$$
\begin{aligned}
T P\left(p, T_{1}\right) & =\frac{(a-b p)}{T}\left[p-\left(M+d+\frac{h}{\theta}\right)\left(\frac{e^{\theta T_{1}}-1}{\theta}\right)\right. \\
- & M \delta T+\left(M \delta+s \delta+d+\frac{h}{\theta}\right) T_{1} \\
& \left.-s \delta\left(\frac{T_{1}^{2}}{2}+\frac{T^{2}}{2}\right)\right]-\frac{O}{T}
\end{aligned}
$$

with $p>w>M>0, T>T_{1}, p \in R^{+}, T_{1} \in R^{+}$.

Proposition 1 For a fixed $T$, the joint supply chain profit $\operatorname{TP}\left(p, T_{1}\right)$ under linear price-sensitive demand is concave with respect to $p$ and $T_{1}$. For $p>w>M$ and $T>T_{\gamma}$ the selling price $p$ and inventory time $T_{1}$ are obtained by solving the following system of equations:

$$
\begin{aligned}
& p=\frac{1}{\delta-1}\left[s \delta\left(T-T_{1}\right)-M\left(e^{\theta T_{1}}-\delta\right)\right. \\
& \left.-(d+h)\left(e^{\theta T_{1}}-1\right)\right] \\
& 1 .
\end{aligned}
$$$$
\begin{aligned}
& {\left[a-\frac{2 b}{\delta-1}\left\{s \delta\left(T-T_{1}\right)-M\left(e^{\theta T_{1}}-\delta\right)\right.\right.} \\
& \left.\left.-(d+h)\left(e^{\theta T_{1}}-1\right)\right\}\right] \times\left\{T_{1}+\left(T-T_{1}\right) \delta\right\} \\
& -b\left[s \delta\left(\Pi_{1}-\frac{T_{1}^{2}}{2}-\frac{T^{2}}{2}\right)\right. \\
& -(h+d+M) \frac{e^{\theta T_{1}}}{\theta}+(h+d)\left(T_{1}+\frac{1}{\theta}\right) \\
& \left.+M\left\{\frac{1}{\theta}-\delta\left(T-T_{1}\right)\right\}\right]=0
\end{aligned}
$$

Proof To find the optimality, differentiating $\operatorname{TP}\left(p, T_{1}\right)$ with respect to $p$ and $T_{1}$ we get the following,

$$
\begin{aligned}
\frac{\partial T P\left(p, T_{1}\right)}{\partial p} & =\frac{(a-2 b p)}{T}\left\{T_{1}+\left(T-T_{1}\right) \delta\right\} \\
- & \frac{b}{T}\left[s \delta\left(T_{1}-\frac{T_{1}^{2}}{2}-\frac{T^{2}}{2}\right)\right. \\
- & (h+d+M) \frac{e^{\theta T_{1}}}{\theta}+(h+d)\left(T_{1}+\frac{1}{\theta}\right) \\
+ & \left.M\left\{\frac{1}{\theta}-\delta\left(T-T_{1}\right)\right\}\right] \\
\frac{\partial T P\left(p, T_{1}\right)}{\partial T_{1}} & =\frac{(a-b p)}{T}\left[p(1-\delta)+s \delta\left(T-T_{1}\right)\right. \\
- & \left.M\left(e^{\theta T_{1}}-\delta\right)-(d+h)\left(e^{\theta T_{1}}-1\right)\right]
\end{aligned}
$$

Equating $\frac{\partial T P\left(p, T_{1}\right)}{\partial T_{1}}=0$ and $\frac{\partial T P\left(p, T_{1}\right)}{\partial p}=0$, we get (18) and (19). Due to the complexity of Eq. (19), it is difficult to show analytically the expression of time-length up to zero inventory $T_{1}$. Using mathematical software, we easily derive $T_{1}$ and shown it numerically.

Total profit $(T P)$ is concave in retail price $(p)$ and timelength up to zero inventory $\left(T_{1}\right)$. The second-order derivative of the profit function is

$$
\begin{aligned}
& \frac{\partial^{2} T P\left(p, T_{1}\right)}{\partial p^{2}}=-\frac{2 b}{T}\left[T_{1}+\left(T-T_{1}\right) \delta\right]<0 \\
& \frac{\partial^{2} T P\left(p, T_{1}\right)}{\partial T_{1}^{2}}=-\frac{(a-2 b p)}{T}\left[s \delta+(d+h+M) \theta e^{\theta T_{1}}\right]<0
\end{aligned}
$$

if $a>2 b p$ holds, since $a>>b$ and $T>T_{1}$ assumed.

To verify the optimality of Eqs. (18) and (19), we calculate the Hessian matrix $(H)$ of the corresponding profit function $\operatorname{TP}\left(p, T_{1}\right)$ is

$$
\mathbf{H}=\left[\begin{array}{ll}
\frac{\partial^{2} T P\left(p, T_{1}\right)}{\partial p^{2}} & \frac{\partial^{2} T P\left(p, T_{1}\right)}{\partial p \partial T_{1}} \\
\frac{\partial^{2} T P\left(p, T_{1}\right)}{\partial T_{1} \partial p} & \frac{\partial^{2} T P\left(p, T_{1}\right)}{\partial T_{1}^{2}}
\end{array}\right]
$$


Here expressions

$$
\begin{aligned}
\frac{\partial^{2} T P\left(p, T_{1}\right)}{\partial p \partial T_{1}}= & \frac{\partial^{2} T P\left(p, T_{1}\right)}{\partial T_{1} \partial p} \\
= & \frac{(1-\delta)}{T}(a-b p)+\frac{b}{T}\left[(d+h)\left(e^{\theta T_{1}}-1\right)\right. \\
& \left.+M\left(e^{\theta T_{1}}-\delta\right)-p(1-\delta)-s \delta\left(T-T_{1}\right)\right]
\end{aligned}
$$

To prove the concavity, we have to show that the Hessian matrix is negative definite, i.e., principal minors alternate their sign starting with a negative sign. Clearly, $\Delta_{1}=\frac{\partial^{2} T P\left(p, T_{1}\right)}{\partial p^{2}}<0$ as $T>T_{1}$.

Since $p>W>M$ and $T>T_{1}, \Delta_{2}>0$ holds (see "Appendix 1", when Eq. (35) satisfy) then the solution set is optimal.

\subsubsection{Supply chain profit under iso-elastic price-sensitive demand}

For $R(p)=\frac{d_{0}}{p^{k}}$ the joint supply chain profit is

$$
\begin{aligned}
T P\left(p, T_{1}\right)= & \frac{d_{0}}{T p^{k}}\left[p-\left(M+d+\frac{h}{\theta}\right)\left(\frac{e^{\theta T_{1}}-1}{\theta}\right)\right. \\
& -M \delta T+\left(M \delta+s \delta+d+\frac{h}{\theta}\right) T_{1} \\
& \left.-s \delta\left(\frac{T_{1}^{2}}{2}+\frac{T^{2}}{2}\right)\right]-\frac{O}{T}
\end{aligned}
$$

with $p>w>M>0, T>T_{1}, p \in R^{+}, T_{1} \in R^{+}$.

Proposition 2 For a fixed $T$, the joint supply chain profit $\operatorname{TP}\left(p, T_{1}\right)$ under iso-elastic price-sensitive demand is concave with respect to $p$ and $T_{1}$. For $p>w>M$ and $T>T_{\gamma}$ the selling price $p$ and inventory time $T_{1}$ are obtained by solving the following system of equations:

$$
\begin{aligned}
& p=\frac{1}{\delta-1}\left[s \delta\left(T-T_{1}\right)-M\left(e^{\theta T_{1}}-\delta\right)\right. \\
& \left.-\quad(d+h)\left(e^{\theta T_{1}}-1\right)\right] \\
& 1 . \\
& (1+k)\left\{T_{1}+\left(T-T_{1}\right) \delta\right\} \\
& -\frac{k \delta(\delta-1)\left(\Pi_{1}-\frac{T_{1}^{2}}{2}-\frac{T^{2}}{2}\right)}{\left[s \delta\left(T-T_{1}\right)-M\left(e^{\theta T_{1}}-\delta\right)-(d+h)\left(e^{\theta T_{1}}-1\right)\right]} \\
& -(h+d+M) \frac{e^{\theta T_{1}}}{\theta}+(h+d)\left(T_{1}+\frac{1}{\theta}\right) \\
& \left.+M\left\{\frac{1}{\theta}-\delta\left(T-T_{1}\right)\right\}\right]=0
\end{aligned}
$$

Proof To find the optimality differentiating total profit $\operatorname{TP}\left(p, T_{1}\right)$ with respect to $p$ and $T_{1}$ we get the following,

$$
\begin{aligned}
\frac{\partial T P\left(p, T_{1}\right)}{\partial p} & =\frac{d_{0}}{T p^{k}}\left\{T_{1}+\left(T-T_{1}\right) \delta\right\} \\
& -\frac{d_{0} k}{T p^{k}}\left[\delta\left(T_{1}-\frac{T_{1}^{2}}{2}-\frac{T^{2}}{2}\right)\right. \\
& -(h+d+M) \frac{e^{\theta T_{1}}}{\theta}+(h+d)\left(T_{1}+\frac{1}{\theta}\right) \\
& \left.+M\left\{\frac{1}{\theta}-\delta\left(T-T_{1}\right)\right\}\right]
\end{aligned}
$$

$$
\begin{array}{r}
\frac{\partial T P\left(p, T_{1}\right)}{\partial T_{1}}=\frac{d_{0} p^{k}}{T}\left[p(1-\delta)+s \delta\left(T-T_{1}\right)\right. \\
\left.-M\left(e^{\theta T_{1}}-\delta\right)-(d+h)\left(e^{\theta T_{1}}-1\right)\right]
\end{array}
$$

Equating $\frac{\partial T P\left(p, T_{1}\right)}{\partial T_{1}}=0$ and $\frac{\partial T P\left(p, T_{1}\right)}{\partial p}=0$, we get (26) and (27).

Again closed form of optimal solutions of $T_{1}$ for iso-elastic demand could not be obtained due to complexity of Eq. (27). So, we derive it numerically in Sect. 3.

The supply chain profit function (TP) is concave in retail price $(p)$ and time-length up to zero inventory $\left(T_{1}\right)$. The second-order derivative under iso-elastic demand pattern are

$$
\begin{aligned}
\frac{\partial^{2} T P\left(p, T_{1}\right)}{\partial p^{2}} & =-\frac{2 d_{0} k}{T p^{k+1}}\left[T_{1}+\delta\left(T-T_{1}\right)\right] \\
+ & \frac{d_{0} k(k+1)}{T p^{k+2}}\left[s \delta\left(T_{1}-\frac{T_{1}^{2}}{2}-\frac{T^{2}}{2}\right)\right. \\
+ & \left.p\left\{T_{1}+\delta\left(T-T_{1}\right)\right\}+M \delta\left(T_{1}-T\right)\right] \\
- & (h+d+M)\left(\frac{e^{\theta T_{1}}-1}{\theta}\right)+(h+d) T_{1} \\
& <0
\end{aligned}
$$

if

$$
\begin{aligned}
& \frac{2 d_{0} k}{T p^{k+1}}\left[T_{1}+\delta\left(T-T_{1}\right)\right]+(h+d+M)\left(\frac{e^{\theta T_{1}}-1}{\theta}\right)> \\
& \frac{d_{0} k(k+1)}{T p^{k+2}}\left[s \delta\left(T_{1}-\frac{T_{1}^{2}}{2}-\frac{T^{2}}{2}\right)+p\left\{T_{1}+\delta\left(T-T_{1}\right)\right\}\right. \\
& \left.+M \delta\left(T_{1}-T\right)\right]+(h+d) T_{1}
\end{aligned}
$$

holds for $p>w>M, T>T_{1}$ and

$\frac{\partial^{2} T P\left(p, T_{1}\right)}{\partial T_{1}^{2}}=-\frac{d_{0}}{T p^{k}}\left[s \delta+(d+h+M) \theta e^{\theta T_{1}}\right]<0$.

To verify the optimality of Eqs. (26) and (27), we calculate the Hessian matrix $(H)$ of the corresponding profit function $T P\left(p, T_{1}\right)$ is 
$\mathbf{H}=\left[\begin{array}{ll}\frac{\partial^{2} T P\left(p, T_{1}\right)}{\partial p^{2}} & \frac{\partial^{2} T P\left(p, T_{1}\right)}{\partial p \partial T_{1}} \\ \frac{\partial^{2} T P\left(p, T_{1}\right)}{\partial T_{1} \partial p} & \frac{\partial^{2} T P\left(p, T_{1}\right)}{\partial T_{1}^{2}}\end{array}\right]$

Here expressions

$$
\begin{aligned}
\frac{\partial^{2} T P\left(p, T_{1}\right)}{\partial p \partial T_{1}}= & \frac{\partial^{2} T P\left(p, T_{1}\right)}{\partial T_{1} \partial p} \\
= & \frac{d_{0}(1-\delta)}{T p^{k}}-\frac{d_{0} k}{T p^{k+1}}\left[(d+h)\left(e^{\theta T_{1}}-1\right)\right. \\
& \left.+M\left(e^{\theta T_{1}}-\delta\right)-p(1-\delta)-s \delta\left(T-T_{1}\right)\right]
\end{aligned}
$$

To prove the concavity, we have to show that hessian matrix is negative definite, i.e., principal minors alternate their sign starting with a negative sign. Clearly, $\Delta_{1}=\frac{\partial^{2} T P\left(p, T_{1}\right)}{\partial p^{2}}<0$ if

$$
\begin{aligned}
& \frac{2 d_{0} k}{T p^{k+1}}\left\{T_{1}+\delta\left(T-T_{1}\right)\right\}+(h+d+M)\left(\frac{e^{\theta T_{1}}-1}{\theta}\right)> \\
& \frac{d_{0} k(k+1)}{T p^{k+2}}\left[s \delta\left(T_{1}-\frac{T_{1}^{2}}{2}-\frac{T^{2}}{2}\right)+p\left\{T_{1}+\delta\left(T-T_{1}\right)\right\}\right. \\
& \left.+M \delta\left(T_{1}-T\right)\right]+(h+d) T_{1}
\end{aligned}
$$

for $p>w>M>0$ and $T>T_{1}$.

Since $p>w>M$ and $T>T_{1}, \Delta_{2}>0$ holds (see "Appendix 2", when Eq. (36) satisfy) then the solution set is optimal.

\section{Algorithm}

1. Start

2. Find $T P_{R}$ and $T P_{M}$, calculating all inventory cost. Then find joint overall supply chain profit $\operatorname{TP}\left(p, T_{1}\right)$ under centralized structure.

3. Evaluate $\frac{\partial T P\left(p, T_{1}\right)}{\partial p}, \frac{\partial T P\left(p, T_{1}\right)}{\partial T_{1}}$ simultaneously.

4. Solve the nonlinear-dependent equations $\frac{\partial T P\left(p, T_{1}\right)}{\partial p}=0$ and $\frac{\partial T P\left(p, T_{1}\right)}{\partial T_{1}}=0$ by initializing the values of $d_{0}, k, a, b$, $M, h, s, d, \theta, \delta$ and $T$.

5. Choose set of solutions from step 4.

6. Evaluate $\frac{\partial^{2} T P\left(p, T_{1}\right)}{\partial^{2} p}, \frac{\partial^{2} T P\left(p, T_{1}\right)}{\partial T_{1}^{2}}$ and $\frac{\partial^{2} T P\left(p, T_{1}\right)}{\partial p \partial T_{1}}$.
7. If the principal minor of the Hessian matrix alternate there sign starting with negative, i.e., $(-1)^{j} \Delta_{j}>0$, here $j=1,2$, then the solution is optimal.

8. Evaluate the selling price $(p)$, time length up to zero inventory $\left(T_{1}\right)$, and then order quantity $(Q)$ as well as total profit of the retailer (TP).

9. End

\section{Numerical results and discussion}

Our mechanism is mainly applicable for the organizations which stored deteriorated items like fruits, vegetables, sweets, and so on. During any season, the demand for these products increases linearly dependent on selling price or sometimes negative power of selling price. One of the popular examples of our anticipated model is (ice-cream factory/ Chocolate factory/bakery/vegetable or food supply chain etc.). Due to the linear and nonlinear behavior of demand, business organizations can adjust their pricing strategy by understanding the market situation and rapid globalization.

\subsection{Numerical example}

In this section, to illustrate the applicability of the proposed model, we study a numerical example considering the values of the input parameters $M=\$ 20, s=\$ 5, T=10$ week are taken from [3], the value of deterioration rate $\theta=0.08$ taken from [15] and some of the key parameters $d_{0}=400000, k=2.2, a=250, b=3.2, \delta=0.7,0=\$ 100$ /order, $h=\$ 4, d=\$ 3$ are logically chosen based on the assumptions presented in Sect. 2.1.

Customer demand for product move proportionately with the price changes. We have shown the sensitivity of the price-elasticity parameter of linear demand $(a, b)$ in Table 5 and price elasticity parameter of iso-elastic demand $(k)$ in Table 6 and discuss the managerial insights in Sect. 3.3.

\subsection{Solution and discussion}

By using software MATHEMATICA, we have evaluated the optimum solutions to maximize total profit $\operatorname{TP}\left(p, T_{1}\right)$ are listed in Table 2. The optimality of the proposed model has been performed considering the cycle length $T=10$ weeks

\begin{tabular}{|c|c|c|c|c|c|c|c|c|}
\hline & \multicolumn{4}{|c|}{ Linear demand } & \multicolumn{4}{|c|}{ Iso-elastic demand } \\
\hline & $p^{*}(\$)$ & $Q^{*}$ (units) & $T_{1}^{*}$ (weeks) & $T P^{*}(\$)$ & $p^{*}(\$)$ & $Q^{*}$ (units) & $T_{1}^{*}$ (weeks) & $T P^{*}(\$)$ \\
\hline$T=10$ weeks & 53.48 & 908.81 & 7.038 & 1761.06 & 52.47 & 761.13 & 6.771 & 1457.89 \\
\hline
\end{tabular}
and then analyze the changes of the optimal solutions under different $T$ value for $T=8,9,11,12$ weeks (shown in Table 4). To illustrate the concavity of the objective function $\operatorname{TP}\left(p, T_{1}\right)$ the sufficient conditions of the profit function have been

Table 2 Optimal solution 
Table 3 Value of second-order derivative

\begin{tabular}{lll}
\hline Sufficient condition check & \\
\hline 2nd order derivative & Under linear form & $\begin{array}{l}\text { Under iso- } \\
\text { elastic form }\end{array}$ \\
\hline$\frac{\partial^{2} T P\left(p, T_{1}\right)}{\partial p^{2}}$ & $-5.8312<0$ & $-1.4072<0$ \\
$\frac{\partial^{2} T P\left(p, T_{1}\right)}{\partial T_{1}^{2}}$ & $-57.517<0$ & $-50.741<0$ \\
$\frac{\partial^{2} T P\left(p, T_{1}\right)}{\partial p^{2}} \frac{\partial^{2} T P\left(p, T_{1}\right)}{\partial T_{1}^{2}}-\left\{\frac{\partial^{2} T P\left(p, T_{1}\right)}{\partial p \partial T_{1}}\right\}^{2}$ & $+329.80>0$ & $+69.676>0$
\end{tabular}

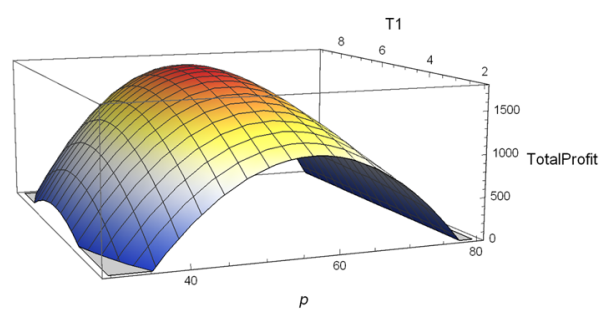

(a) Total profit $T P\left(p, T_{1}\right)$ with respect to $p$ and $T_{1}$ under linear price sensitive demand.

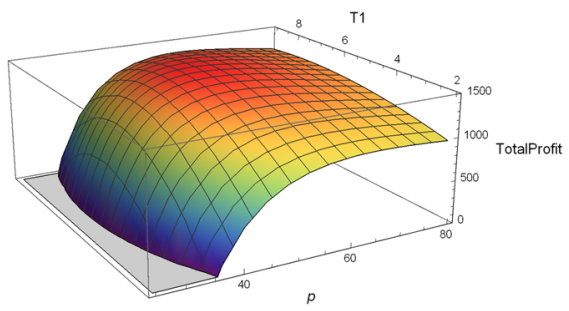

(b) Total profit $T P\left(p, T_{1}\right)$ with respect to $p$ and $T_{1}$ under iso-elastic price sensitive demand.

Fig. 3 Concavity curve of profit function

evaluated in Table 3. The numerical illustration may help to elucidate the comparisons between linear and nonlinear behavior of demand functions.

Comparing the results of the supply chain for two different demand strategies, we find that the retail price in a linear price-sensitive demand scenario is higher than that of the iso-elastic price-sensitive demand scenario. Meanwhile, the order quantity and time-length to stock out the products as well as the total profit under linear price-sensitive demand are greater than those of iso-elastic demand pattern.

Figure 3a shows the concavity of total profit $T P\left(p, T_{1}\right)$ with respect to $p$ and $T_{1}$ under linear price-sensitive demand. Employing the suggested solution algorithm and the result of the proposed mechanism shown in Table 2, if the retailer sells the product at $p=\$ 53.48$ then the stock out time of products in retailer's inventory will be $T_{1}=7.038$ weeks and the supply chain will achieve it's highest profit \$1761.06 employing the sufficient conditions of Table 3.

Similarly, Fig. 3b shows the concavity of total profit $\operatorname{TP}\left(p, T_{1}\right)$ under iso-elastic price-sensitive demand. From optimal Table 2, it is clear that if the retailer sells the product at $p=\$ 52.47$ and able to sells the product at time $T_{1}=6.771$ weeks, then the supply chain will achieve its highest profit \$1457.89 employing the sufficient conditions of Table 3.

From Table 4, it is interesting to show the variation of cycle duration $T$ on optimal profit under linear and isoelastic price-sensitive demand scenario. Keeping order quantity as low as possible for a short duration of the cycle, save money on holding and other costs associated with the item. Also the retailer sells the product at a lower selling price as he invests less on inventory costs. But the shortened cycle duration is profitable for an organization's supply chain model. An increase in cycle length sustained high-order quantity call for an increase in other costs associated with that item. So stock-outs of items are costly and they represent the lost sales and failure of supply chain coordination for both demand patterns.

\subsection{Sensitivity analysis}

Tables 4, 5, 6, 7, 8, 9 and 10 and Figs. 4 and 5 show the impact of the percentage change of different cost parameters $M, h, d$, s on optimal selling price ( $p)$, optimal order quantity $(Q)$, optimal time-length up to zero inventory $\left(T_{1}\right)$ and total supply chain profit (TP). The analysis is conducted by changing the value of one of the parameters by $-30 \%$, $-15 \%,+15 \%$ and $+30 \%$, respectively, keeping the other parameters constant.
Table 4 Sensitivity analysis with respect to cycle duration $T$

\begin{tabular}{|c|c|c|c|c|c|c|c|c|}
\hline & \multicolumn{4}{|c|}{ Linear demand } & \multicolumn{4}{|c|}{ Iso-elastic demand } \\
\hline & $p^{*}(\$)$ & $Q^{*}$ (units) & $T_{1}^{*}$ (weeks) & $T P^{*}(\$)$ & $p^{*}(\$)$ & $Q^{*}$ (units) & $T_{1}^{*}$ (weeks) & $T P^{*}(\$)$ \\
\hline$T=8$ weeks & 52.65 & 743.62 & 6.023 & 1910.22 & 49.14 & 684.27 & 5.623 & 1584.46 \\
\hline$T=9$ weeks & 53.05 & 827.10 & 6.535 & 1834.80 & 50.78 & 725.92 & 6.203 & 1519.40 \\
\hline$T=10$ weeks & 53.48 & 908.81 & 7.038 & 1761.06 & 52.47 & 761.13 & 6.771 & 1457.89 \\
\hline$T=11$ weeks & 53.91 & 988.50 & 7.531 & 1688.60 & 54.20 & 790.61 & 7.328 & 1399.60 \\
\hline$T=12$ weeks & 54.37 & 1065.91 & 8.014 & 1617.36 & 55.95 & 814.99 & 7.874 & 1344.50 \\
\hline
\end{tabular}


Table 5 Sensitivity analysis with respect to linear price elasticity $a$ and $b$

\begin{tabular}{cllllr}
\hline \multirow{5}{*}{$a=280$} & \multicolumn{4}{l}{ Linear demand } & \\
\cline { 2 - 6 } & $b$ & $p^{*}(\$)$ & $Q^{*}$ (units) & $T_{1}^{*}$ (weeks) & $T P^{*}(\$)$ \\
\hline \multirow{6}{*}{$a=250$} & 53.30 & 1014.60 & 7.03 & 1954.47 \\
& 3.4 & 55.60 & 1055.50 & 7.12 & 2208.65 \\
& 3.2 & 58.25 & 1098.05 & 7.23 & 2500.09 \\
& 3.0 & 61.23 & 1142.70 & 7.35 & 2836.47 \\
& 2.8 & 64.63 & 1189.92 & 7.49 & 3227.74 \\
& 3.6 & 49.07 & 831.21 & 6.85 & 1343.35 \\
& 3.4 & 51.14 & 869.38 & 6.94 & 1537.48 \\
& 3.2 & 53.48 & 908.81 & 7.03 & 1761.06 \\
& 3.0 & 56.12 & 949.87 & 7.15 & 2020.13 \\
& 2.8 & 59.16 & 992.90 & 7.27 & 2322.52 \\
& 3.6 & 44.85 & 652.95 & 6.68 & 847.34 \\
& 3.4 & 46.67 & 688.75 & 6.75 & 988.38 \\
& 3.2 & 48.72 & 725.53 & 6.84 & 1152.33 \\
& 3.0 & 51.04 & 763.49 & 6.94 & 1343.49 \\
& 2.8 & 53.70 & 803.00 & 7.05 & 1567.88 \\
\hline
\end{tabular}

Table 6 Sensitivity analysis with respect to iso-elastic price elasticity $k$

\begin{tabular}{lllll}
\hline & \multicolumn{4}{l}{ Linear demand } \\
\cline { 2 - 5 } & $p^{*}(\$)$ & $Q^{*}$ (units) & $T_{1}^{*}$ (weeks) & $T P^{*}(\$)$ \\
\hline$k$ & & & & \\
2.0 & 57.38 & 1419.50 & 6.90 & 3258.80 \\
2.1 & 54.70 & 1041.23 & 6.82 & 2175.60 \\
2.2 & 52.47 & 761.13 & 6.77 & 1457.89 \\
2.3 & 50.60 & 554.85 & 6.72 & 979.70 \\
2.4 & 49.00 & 403.57 & 6.68 & 659.58 \\
\hline
\end{tabular}

Table 5 shows the impact of changes of $a, b$ for linear demand and table 6 shows impact of changes of $k$ for iso-elastic demand in total profit TP and decision variables. We change the initial value of some particular parameters $(a, b, k)$ keeping other parametric values unchanged at that time.

Results of sensitivity analysis have revealed that there is a significant effect of change in the values of duration of cycle $T$ and cost parameters $M, h, d$, s on the optimal Net Profit (TP) as well as on the optimal values of the decision variables which are shown in Figs. 4 and 5 .

Based on Tables 4, 5, 6, 7, 8, 9 and 10 and Figs. 4 and 5, we have the following managerial insights according to change the behavior of different parameters.

1. As the manufacturing cost $(M)$ increases, the selling price $(p)$ of the retailer increases, ordering lot size $(Q)$ of the manufacturer, time-length up to zero inventory $\left(T_{1}\right)$ of retailer warehouse and the total profit $(T P)$ of the supply chain decreases as shown in Table 7 and Figs. $4 a$, e and 5a. From an economic viewpoint, when manufacturing cost increases retailer prefers to raise its selling price to chase more benefits. But under both linear and nonlinear demand, the rate of change of selling price, ordering lot size is different. Increasing manufacturing cost leads to a very low demand under iso-elastic price-sensitive demand pattern compared to linear price-sensitive demand and fewer products have sold out at less time which prompts the retailer to increase its selling price at a higher rate in case of iso-elastic demand pattern, as a result, this affects a negative impact on total supply chain profit. The total profit for the iso-elastic demand form is very less com-
Table 7 Sensitivity analysis with respect to manufacturing cost $M$

Table 8 Sensitivity analysis with respect to holding cost $h$

\begin{tabular}{|c|c|c|c|c|c|c|c|c|c|c|}
\hline & \multirow[t]{2}{*}{ Value } & \multirow[t]{2}{*}{ \% Change } & \multicolumn{4}{|c|}{ Linear demand } & \multicolumn{4}{|c|}{ Iso-elastic demand } \\
\hline & & & $p^{*}(\$)$ & $Q^{*}$ (units) & $T_{1}^{*}$ (weeks) & $T P^{*}(\$)$ & $p^{*}(\$)$ & $Q^{*}$ (units) & $T_{1}^{*}$ (weeks) & $T P^{*}(\$)$ \\
\hline \multirow[t]{5}{*}{ M } & 26 & +30 & 56.94 & 735.68 & 6.377 & 1269.23 & 65.58 & 453.70 & 6.430 & 1105.05 \\
\hline & 23 & +15 & 55.22 & 818.45 & 6.692 & 1502.18 & 59.06 & 578.54 & 6.593 & 1258.78 \\
\hline & 20 & 0 & 53.48 & 908.81 & 7.038 & 1761.06 & 52.47 & 761.13 & 6.771 & 1457.89 \\
\hline & 17 & -15 & 51.71 & 1008.50 & 7.419 & 2048.40 & 45.80 & 1042.60 & 6.965 & 1725.20 \\
\hline & 14 & -30 & 49.94 & 1120.18 & 7.843 & 2367.38 & 40.12 & 1416.51 & 7.150 & 2099.32 \\
\hline
\end{tabular}

\begin{tabular}{|c|c|c|c|c|c|c|c|c|c|c|}
\hline & \multirow[t]{2}{*}{ Value } & \multirow[t]{2}{*}{$\%$ Change } & \multicolumn{4}{|c|}{ Linear demand } & \multicolumn{4}{|c|}{ Iso-elastic demand } \\
\hline & & & $p^{*}(\$)$ & $Q^{*}$ (units) & $T_{1}^{*}$ (weeks) & $T P^{*}(\$)$ & $p^{*}(\$)$ & $Q^{*}$ (units) & $T_{1}^{*}$ (weeks) & $T P^{*}(\$)$ \\
\hline \multirow[t]{5}{*}{$\mathrm{h}$} & 5.2 & +30 & 53.58 & 895.14 & 6.920 & 1738.70 & 52.89 & 742.06 & 6.672 & 1440.84 \\
\hline & 4.6 & +15 & 53.53 & 901.88 & 6.978 & 1749.76 & 52.68 & 751.44 & 6.721 & 1449.26 \\
\hline & 4 & 0 & 53.48 & 908.81 & 7.038 & 1761.06 & 52.47 & 761.13 & 6.771 & 1457.89 \\
\hline & 3.4 & -15 & 53.42 & 915.93 & 7.098 & 1772.59 & 52.26 & 771.16 & 6.822 & 1466.75 \\
\hline & 2.8 & -30 & 53.36 & 923.25 & 7.160 & 1784.38 & 52.04 & 781.53 & 6.873 & 1475.84 \\
\hline
\end{tabular}


Table 9 Sensitivity analysis with respect to deterioration cost $d$

\begin{tabular}{|c|c|c|c|c|c|c|c|c|c|c|}
\hline & \multirow[t]{2}{*}{ Value } & \multirow[t]{2}{*}{$\%$ Change } & \multicolumn{4}{|c|}{ Linear demand } & \multicolumn{4}{|c|}{ Iso-elastic demand } \\
\hline & & & $p^{*}(\$)$ & $Q^{*}$ (units) & $T_{1}^{*}$ (weeks) & $T P^{*}(\$)$ & $p^{*}(\$)$ & $Q^{*}$ (units) & $T_{1}^{*}$ (weeks) & $T P^{*}(\$)$ \\
\hline \multirow[t]{5}{*}{ d } & 3.9 & +30 & 53.56 & 898.49 & 6.949 & 1744.20 & 52.79 & 746.71 & 6.696 & 1445.02 \\
\hline & 3.45 & +15 & 53.51 & 903.59 & 6.993 & 1752.57 & 52.63 & 753.83 & 6.733 & 1451.40 \\
\hline & 3 & 0 & 53.48 & 908.81 & 7.038 & 1761.06 & 52.47 & 761.13 & 6.771 & 1457.89 \\
\hline & 2.55 & -15 & 53.43 & 914.13 & 7.083 & 1769.69 & 52.31 & 768.62 & 6.809 & 1464.51 \\
\hline & 2.1 & -30 & 53.39 & 919.56 & 7.129 & 1778.45 & 52.15 & 776.30 & 6.847 & 1471.26 \\
\hline
\end{tabular}

\begin{tabular}{|c|c|c|c|c|c|c|c|c|c|c|}
\hline & \multirow[t]{2}{*}{ Value } & \multirow[t]{2}{*}{ \% Change } & \multicolumn{4}{|c|}{ Linear demand } & \multicolumn{4}{|c|}{ Iso-elastic demand } \\
\hline & & & $p^{*}(\$)$ & $Q^{*}$ (units) & $T_{1}^{*}$ (weeks) & $T P^{*}(\$)$ & $p^{*}(\$)$ & $Q^{*}$ (units) & $T_{1}^{*}$ (weeks) & $T P^{*}(\$)$ \\
\hline \multirow[t]{5}{*}{5} & 6.5 & +30 & 53.85 & 927.36 & 7.421 & 1729.68 & 53.95 & 743.23 & 6.235 & 1423.74 \\
\hline & 5.75 & +15 & 53.67 & 918.66 & 7.243 & 1744.23 & 53.21 & 752.82 & 6.503 & 1432.10 \\
\hline & 5 & 0 & 53.48 & 908.81 & 7.038 & 1761.06 & 52.47 & 761.13 & 6.771 & 1457.89 \\
\hline & 4.25 & -15 & 53.24 & 897.53 & 6.796 & 1780.80 & 51.52 & 773.90 & 6.470 & 1480.84 \\
\hline & 3.5 & -30 & 52.96 & 884.47 & 6.508 & 1804.31 & 50.36 & 790.84 & 6.101 & 1509.82 \\
\hline
\end{tabular}

Table 10 Sensitivity analysis with respect to shortage cost $s$ approximately the same for increasing deterioration cost.

4. As the shortage cost $(s)$ increases as shown in Table 10 and Figs. $4 d$, $h$ and $5 c$, selling price $(p)$, inventory time $\left(T_{1}\right)$ increases under both the demand pattern. But with the changes in shortage cost, order quantity $(Q)$ will increase under the linear demand policy while it decreases under the iso-elastic demand policy. Moreover, increasing shortage cost (due to various phenomenon like a quantity discount, price discount, offering facility, an opportunity of delay in payment, etc.) always reduce supply chain profitability under both the demand analysis.

5. It is observed that when $a$ increases in linear demand pattern, market demand will be increased. It indicates the instantaneous growth of ordering lot size. As a result, the time-length to stock out the product is lengthier and organizations sell the more product at more selling price and get higher profit shown in Table 5.

6. When price-elasticity parameters for both linear and iso-elastic demand $(b, k)$ increases demand decreases. The organization will bring down the retail price and order amount. Fewer products are stock out at less time. Due to the fixed replenishment cycle, shortage period is lengthened. All these behavior of the priceelasticity parameter $b, k$ decreases the total profit $(T P)$ of the supply chain shown in Tables 5 and 6. demand on the rate of change of optimal solutions is 
Fig. 4 Changes of $p$ and $Q$ with respect to $M, h, d$ and $s$

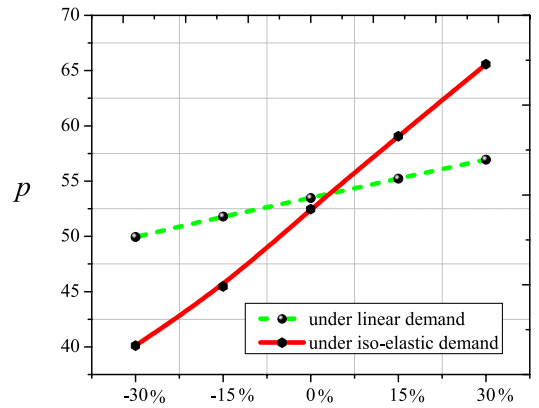

percentage (\%) change of parameter $\mathrm{M}$

(a) $M$ vs. $p$

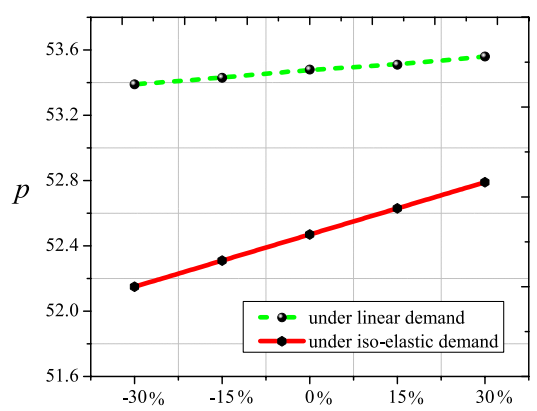

percentage $(\%)$ change of parameter $\mathrm{d}$

(c) $d$ vs. $p$

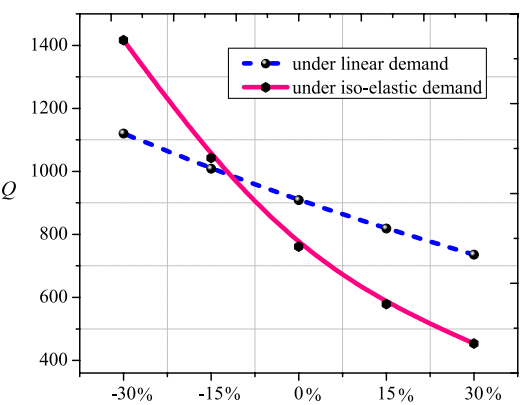

percentage (\%) change of parameter $\mathrm{M}$

(e) $M$ vs. $Q$

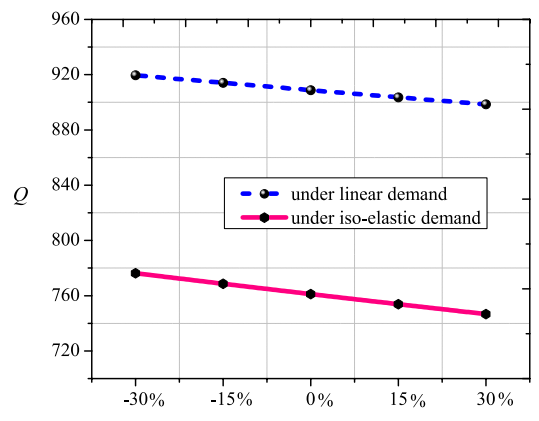

percentage $(\%)$ change of parameter $d$

(g) $d$ vs. $Q$

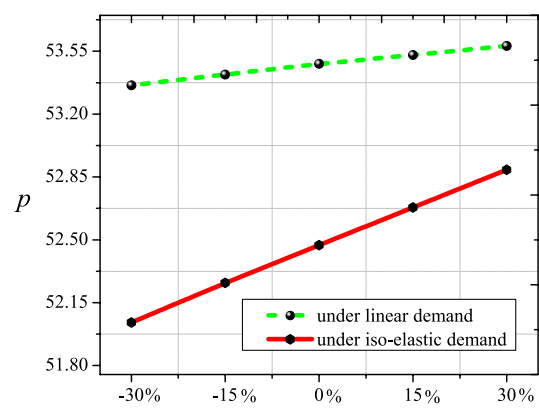

percentage $(\%)$ change of parameter $h$

(b) $h$ vs. $p$

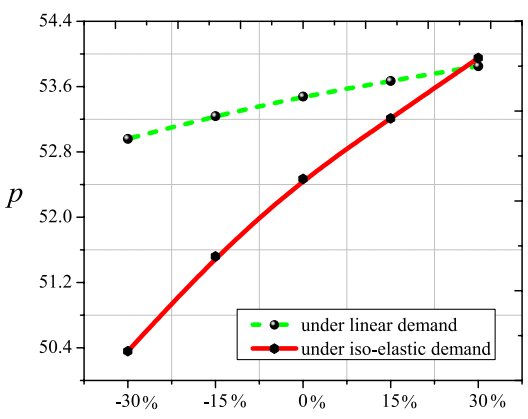

percentage $(\%)$ change of parameter $\mathrm{s}$

(d) $s$ vs. $p$

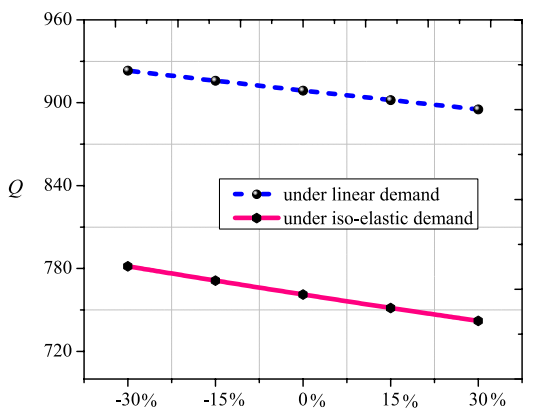

percentage $(\%)$ change of parameter $h$

(f) $h$ vs. $Q$

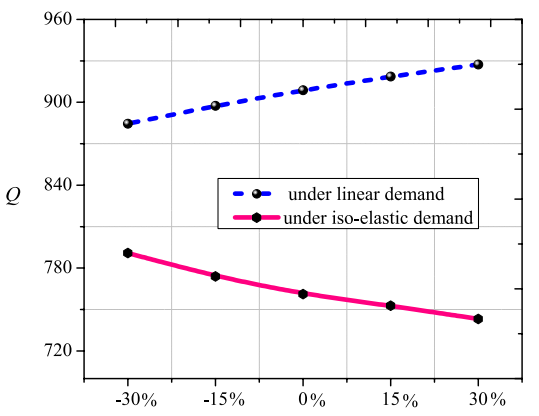

percentage $(\%)$ change of parameter $\mathrm{s}$

(h) $s$ vs. $Q$ 
Fig. 5 Changes of Total profit (TP) with respect to $M, h, d$ and $s$

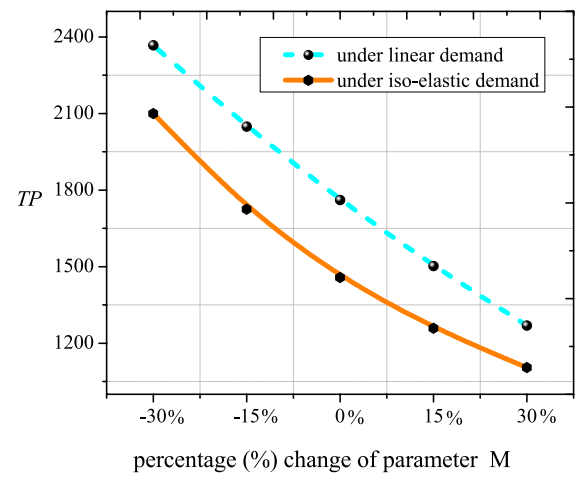

(a) $M$ vs. $T P$

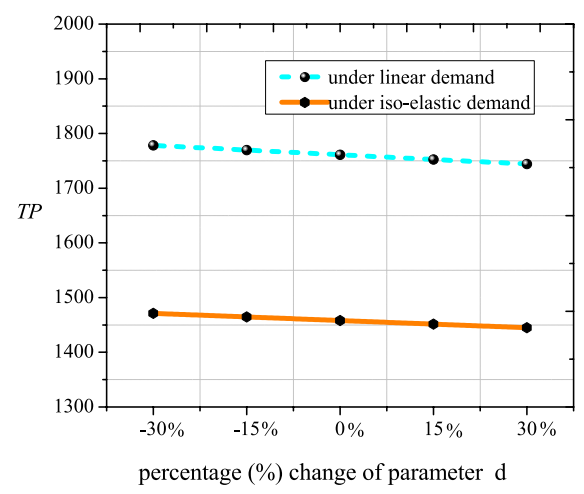

(c) $d$ vs. $T P$

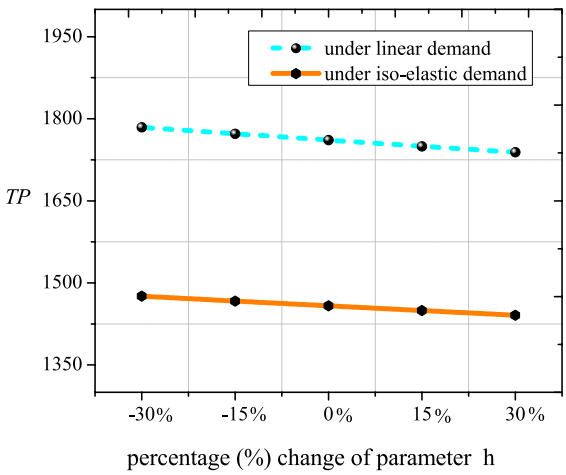

(b) $h$ vs. $T P$

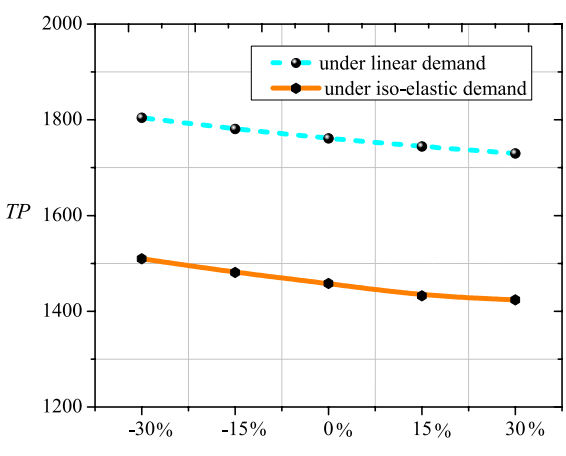

percentage $(\%)$ change of parameter $\mathrm{s}$

(d) $s$ vs. $T P$

\section{Conclusion}

In this article, we have considered a two-echelon supply chain comprising of a manufacturer and a retailer for two different demand functions. The demand function of the customer is linearly dependent on selling price and isoelastic form of the selling price. The manufacturer offers the product to the retailer and at retailer warehouse products are deteriorated at a constant deterioration rate. The shortage also occurs at the retailer warehouse which is partially backlogged with a backlogging rate $\delta$. Under these circumstances, the joint profit function of the channel members of the supply chain is discussed. We have developed two models under two different patterns and compare the total profit under a joint centralized strategy. The key decision variables of our proposed model are the selling price of the retailer, optimal time-length up to zero inventory, total supply chain profit by which the organization can invest securely for different demand patterns. In our model, we assume the total duration of the cycle to be fixed and discuss the profitability of a coordinated organization by showing the impact of different time-length of the cycle in Table 4.
A numerical example has been solved to demonstrate the proposed algorithm. Through the comparison of two different demand scenarios, the retailer sells the product at a higher selling price for a fixed period in case of linear pricesensitive demand compared to the iso-elastic price-sensitive form. Moreover, higher selling price and more ordering lot size lead to more profit in linear price-sensitive demand.

Sensitivity of some key parameters has been analyzed which will give an option in contrast to given strategies in the area of supply chain management and construct the route for a more extensive application extent of the model. The result shows that the change of some input parameters has a significant impact on the optimal decisions of the supply chain system. Total profit of the supply chain decreases for increasing holding cost, deterioration cost, shortage cost and manufacturing cost. But,the decreasing rate of total profit is high for increasing manufacturing cost which indicates that a lower manufacturing cost is more beneficial for the joint supply chain system. In case of demand elasticity parameter, the increasing market potential is always beneficial for the supply chain system but increasing price-elasticity parameter value for both the demand pattern causes a loss for the system. 
The new major contribution of this paper is a comparison of joint profit and optimal decisions under linear and iso-elastic demand form and also consideration of deterioration, shortage of product at retailer warehouse compared to the existing literature. This model is applicable for the deteriorated products like fruits, vegetables, etc. when the market decisions are taken together by both manufacturer/supplier and retailer.

In this paper, both the manufacturer and retailer are decision-makers and they jointly optimize their profit under different demand patterns but we have not discussed our model if any of the channel members may not accept to participate in the joint centralized model which is a limitation of our model. Different incentive plans could be considered including a decentralized decision model in the future direction. Another limitation is the constant deterioration rate which is very common in literature. We may extend our model considering time-dependent deterioration at the retailer warehouse and for a multi-stage supply chain.

Acknowledgements Authors of this paper express gratitude to the Hon'ble reviewers for their valuable comments. After addressing and incorporating these comments, the quality of the paper definitely enhanced.

\section{Compliance with ethical standards}

Conflict of interest The authors declare that they have no competing interests.

\section{Appendix 1}

$$
\begin{aligned}
& \triangle_{2}=\frac{\partial^{2} T P\left(p, T_{1}\right)}{\partial p^{2}} \frac{\partial^{2} T P\left(p, T_{1}\right)}{\partial T_{1}^{2}}-\left\{\frac{\partial^{2} T P\left(p, T_{1}\right)}{\partial p \partial T_{1}}\right\}^{2} \\
& =\frac{2 b(a-2 b p)}{T^{2}}\left\{T_{1}+\left(T-T_{1}\right) \delta\right\} \\
& \times\left\{s \delta+(d+h+M) \theta e^{\theta T_{1}}\right\} \\
& -\left\{\frac{(1-\delta)}{T}(a-b p)+\frac{b}{T}\left[(d+h)\left(e^{\theta T_{1}}-1\right)\right.\right. \\
& \left.\left.+M\left(e^{\theta T_{1}}-\delta\right)-p(1-\delta)-s \delta\left(T-T_{1}\right)\right]\right\}^{2}>0
\end{aligned}
$$

Due to complexities of Eq. (35) the condition of $\triangle_{2}>0$ holds if $T>T_{1}$ and $p>W>M$ is verified numerically on Sect. 3 and also shown the concavity in Fig. 3 a.

\section{Appendix 2}

$$
\begin{aligned}
\triangle_{2} & =\frac{\partial^{2} T P\left(p, T_{1}\right)}{\partial p^{2}} \frac{\partial^{2} T P\left(p, T_{1}\right)}{\partial T_{1}^{2}}-\left\{\frac{\partial^{2} T P\left(p, T_{1}\right)}{\partial p \partial T_{1}}\right\}^{2} \\
& =\left\{-\frac{2 d_{0} k}{T p^{k+1}}\left[T_{1}+\delta\left(T-T_{1}\right)\right]+\frac{d_{0} k(k+1)}{T p^{k+2}}\right. \\
& {\left[s \delta\left(T_{1}-\frac{T_{1}^{2}}{2}-\frac{T^{2}}{2}\right)+p\left\{T_{1}+\delta\left(T-T_{1}\right)\right\}\right.} \\
& \left.\left.+M \delta\left(T_{1}-T\right)\right]-(h+d+M)\left(\frac{e^{\theta T_{1}}-1}{\theta}\right)+(h+d) T_{1}\right\} \\
& \times\left\{-\frac{d_{0}}{T p^{k}}\left[s \delta+(d+h+M) \theta e^{\theta T_{1}}\right]\right\} \\
- & \left\{\frac{d_{0}(1-\delta)}{T p^{k}}-\frac{d_{0} k}{T p^{k+1}}\left[(d+h)\left(e^{\theta T_{1}}-1\right)\right.\right. \\
& \left.\left.+M\left(e^{\theta T_{1}}-\delta\right)-p(1-\delta)-s \delta\left(T-T_{1}\right)\right]\right\}^{2}>0
\end{aligned}
$$

Again $\Delta_{2}>0$ is verified numerically in our numeric setting if $T>T_{1}, p>w>M$ and shown the concavity in Fig. $3 \mathrm{~b}$.

\section{References}

1. Agrawal AK, Yadav S (2020) Price and profit structuring for single manufacturer multi-buyer integrated inventory supply chain under price-sensitive demand condition. Comput Ind Eng 139:106208

2. Alfares HK, Ghaithan AM (2016) Inventory and pricing model with price-dependent demand, time-varying holding cost, and quantity discounts. Comput Ind Eng 94:170-177

3. Arcelus F, Kumar S, Srinivasan G (2008) Pricing and rebate policies in the two-echelon supply chain with asymmetric information under price-dependent, stochastic demand. Int J Prod Econ 113(2):598-618

4. Barman A, Das R, De PK (2020) Pricing and inventory policy for deteriorating item in a two-echelon supply chain: a stackelberg duopoly game approach. In: 2020 8th international conference on reliability, infocom technologies and optimization (trends and future directions)(ICRITO). IEEE, pp 796-800

5. Cheng MC, Hsieh TP, Lee HM, Ouyang LY (2020) Optimal ordering policies for deteriorating items with a return period and price-dependent demand under two-phase advance sales. Oper Res Int J 20(2):585-604

6. Das BC, Das B, Mondal SK (2013) Integrated supply chain model for a deteriorating item with procurement cost dependent credit period. Comput Ind Eng 64(3):788-796

7. Dong JF, Shao-Fu D, Yang S, Liang L (2008) Competitive pricing and replenishment policies in distributed supply chain for a deteriorating item: a game approach. Asia Pac Manag Rev 13(2):497-512 
8. Feng L, Chan YL, Cárdenas-Barrón LE (2017) Pricing and lot-sizing polices for perishable goods when the demand depends on selling price, displayed stocks, and expiration date. Int J Prod Econ 185:11-20

9. Feng L, Zhang J, Tang W (2015) A joint dynamic pricing and advertising model of perishable products. J Oper Res Soc 66(8):1341-1351

10. Giri B, Bardhan S (2016) Coordinating a two-echelon supply chain with environmentally aware consumers. Int J Manag Sci Eng Manag 11(3):178-185

11. Hou J, Zeng AZ, Zhao L (2009) Achieving better coordination through revenue sharing and bargaining in a two-stage supply chain. Comput Ind Eng 57(1):383-394

12. Hsieh TP, Dye CY (2017) Optimal dynamic pricing for deteriorating items with reference price effects when inventories stimulate demand. Eur J Oper Res 262(1):136-150

13. Lau AHL, Lau HS (2003) Effects of a demand-curve's shape on the optimal solutions of a multi-echelon inventory/pricing model. Eur J Oper Res 147(3):530-548

14. Mahata P, Mahata GC, Mukherjee A (2019) An ordering policy for deteriorating items with price-dependent iso-elastic demand under permissible delay in payments and price inflation. Math Comput Model Dyn Syst 25(6):575-601

15. Maihami R, Kamalabadi IN (2012) Joint pricing and inventory control for non-instantaneous deteriorating items with partial backlogging and time and price dependent demand. Int J Prod Econ 136(1):116-122

16. Maiti T, Giri B (2015) A closed loop supply chain under retail price and product quality dependent demand. J Manuf Syst 37:624-637

17. Mashud AHM, Uddin MS, Sana SS (2019) A two-level trade-credit approach to an integrated price-sensitive inventory model with shortages. Int J Appl Comput Math 5(4):121

18. Mukhopadhyay S, Mukherjee R, Chaudhuri K (2004) Joint pricing and ordering policy for a deteriorating inventory. Comput Ind Eng 47(4):339-349

19. Pal B, Sana SS, Chaudhuri K (2016) Two-echelon competitive integrated supply chain model with price and credit period dependent demand. Int J Syst Sci 47(5):995-1007
20. Rameswari M, Uthayakumar R (2018) An integrated inventory model for deteriorating items with price-dependent demand under two-level trade credit policy. Int J Syst Sci Oper Log 5(3):253-267

21. Saha S, Goyal S (2015) Supply chain coordination contracts with inventory level and retail price dependent demand. Int J Prod Econ 161:140-152

22. Shah NH, Chaudhari U, Cárdenas-Barrón LE (2020) Integrating credit and replenishment policies for deteriorating items under quadratic demand in a three echelon supply chain. Int J Syst Sci Oper $\log 7(1): 34-45$

23. Taleizadeh AA, Noori-daryan M (2016) Pricing, manufacturing and inventory policies for raw material in a three-level supply chain. Int J Syst Sci 47(4):919-931

24. Teng JT, Cárdenas-Barrón LE, Chang HJ, Wu J, Hu Y (2016) Inventory lot-size policies for deteriorating items with expiration dates and advance payments. Appl Math Model 40(19-20):8605-8616

25. Tiwari S, Cárdenas-Barrón LE, Goh M, Shaikh AA (2018) Joint pricing and inventory model for deteriorating items with expiration dates and partial backlogging under two-level partial trade credits in supply chain. Int J Prod Econ 200:16-36

26. Tiwari S, Jaggi CK, Gupta M, Cárdenas-Barrón LE (2018) Optimal pricing and lot-sizing policy for supply chain system with deteriorating items under limited storage capacity. Int J Prod Econ 200:278-290

27. Wang X, Li D (2012) A dynamic product quality evaluation based pricing model for perishable food supply chains. Omega 40(6):906-917

28. Zhou YW, Min J, Goyal SK (2008) Supply-chain coordination under an inventory-level-dependent demand rate. Int J Prod Econ 113(2):518-527

Publisher's Note Springer Nature remains neutral with regard to jurisdictional claims in published maps and institutional affiliations. 